\title{
Measuring Coaching in Undergraduate Medical Education: the Development and Psychometric Validation of New Instruments
}

\author{
Patricia A. Carney, PhD, Erin M. Bonura, MD, Jeff A. Kraakevik, MD, Amy Miller Juve, EdD, \\ Leslie E. Kahl, MD, and Nicole M. Deiorio, MD
}

Oregon Health \& Science University, Portland, OR, USA.

\begin{abstract}
BACKGROUND: Coaching is emerging as a novel approach to guide medical students toward becoming competent, reflective physicians and master adaptive learners. However, no instruments currently exist to measure academic coaching at the undergraduate medical education level. OBJECTIVE: To describe the development and psychometric assessments of two instruments designed to assess academic coaching of medical students toward creating a robust measurement model of this educational paradigm.
\end{abstract}

DESIGN: Observational psychometric.

PARTICIPANTS: All medical students in the 2014 and 2015 cohorts and all their coaches were invited to complete the instruments being tested, which led to 662 medical student responses from 292 medical students and 468 coaching responses from 22 coaches being included in analyses. Medical student response rates were $75.7 \%$ from 2014 and $75.5 \%$ from 2015. Overall, the coaches' response rate was $71 \%$.

MAIN MEASURES: Two 31-item instruments were initially developed, one for medical students to assess their coach and one for faculty coaches to assess their students, both of which evaluated coaching based on definitions we formulated using existing literature. Each was administered to two cohorts of medical students and coaches in 2015 and 2016. An exploratory factor analysis using principal component analysis as the extraction method and Varimax with Kaiser normalization as the rotation method was conducted.

KEY RESULTS: Eighteen items reflecting four domains were retained with eigenvalues higher than 1.0 for medical students' assessment of coaching, which measured promoting self-monitoring, relationship building, promoting reflective behavior, and establishing foundational ground rules. Sixteen items reflecting two domains were retained for the faculty assessment of coaching with eigenvalues higher than 1.0: the Practice of Coaching and Relationship Formation.

CONCLUSIONS: We successfully developed and psychometrically validated surveys designed to measure key aspects of the coaching relationship, coaching processes, and reflective outcomes. The new validated instruments offer a robust measurement model for academic coaching.

Electronic supplementary material The online version of this article (https://doi.org/10.1007/s11606-019-04888-w) contains supplementary material, which is available to authorized users.

Published online April 16, 2019
KEY WORDS: undergraduate medical education; academic coaching.

J Gen Intern Med 34(5):677-83

DOI: $10.1007 / \mathrm{s} 11606-019-04888-\mathrm{w}$

(c) Society of General Internal Medicine 2019

\section{INTRODUCTION}

Coaching is emerging as a novel approach to guide medical students toward becoming competent, reflective physicians ${ }^{1,2}$ and master adaptive learners, ${ }^{3}$ especially among schools undertaking time-varying competency-based curriculum. ${ }^{4}$ Traditional models of providing student support (mentoring and advising) use paradigms that tend to be more faculty-driven, while coaching is learner-driven.$^{5-7}$ Our prior work on the definitions of coaching and possible constructs has been reported elsewhere. ${ }^{1}$

We implemented a coaching program at Oregon Health \& Science University (OHSU) in 2014, where medical students are assigned an academic coach based on areas of professional interest. Each coach works with five assigned students from each year of our curriculum. Coaches apply for their roles and coaches and are selected after an interview process occurs. They receive 0.1 FTE of protected time, which covers (1) monthly meetings with individual students, (2) small group meetings with students across the entire program, and (3) monthly faculty development sessions on coaching.

Coaches use individual meetings to help students set and achieve concrete goals. These goals, as well as academic performance and attainment of student competencies, are tracked using an electronic portfolio specifically designed to support our curriculum's individualized approach to medical education. This system is used by coaches in their work with medical students along with a coaching documentation system.

Significant faculty development occurs for coaches, paying attention to the differences between coaching, advising, mentoring, and other forms of learner support. We emphasize that coaching must occur and ask faculty to track goals and outcomes of the coaching meetings.

What is needed now, however, is a measurement model that includes instruments with demonstrated validity and reliability that measure the coaching relationship, its associated processes, and outcomes, such as reflective learning development, during undergraduate medical education. Such instruments will allow 
us to assess longitudinal aspects of coaching, as well as how these constructs affect learners' ability to self-reflect and selfmonitor over time, and how coaching contributes to academic success, career satisfaction, continuous professional development, community service, well-being, and, ultimately, patient care and related health outcomes. Here, we present the development and validation of two instruments: (1) student assessments of their coach and (2) coach assessments of their student. We include finalized instruments based on our findings.

\section{METHODS}

\section{Instrument Development}

Toward the development of measures to assess coaching, we undertook an extensive evaluation of the coaching literature in many fields (e.g., sports and executive coaching) to solidify a definition of coaching applied to medical education and identify possible concepts of coaching in this paradigm. ${ }^{1,5-7}$ This information is published in a prior paper. ${ }^{1}$ We defined academic coaching as a developmental process whereby an individual learner meets regularly over time with a faculty coach to create goals, identify strategies to manage existing and potential challenges, improve academic performance, and develop professional identity toward reaching the learner's highest potential. ${ }^{1}$ We identified four possible coaching constructs: (1) establishing relationship principles, (2) conducting learner assessments, (3) developing and implementing an action plan, and (4) assessing results and revising plans accordingly, which are based on the work of Cummings and Worley from the executive coaching literature. ${ }^{7}$ We amassed 31 items for each instrument that we thought reflected the proposed academic coaching constructs, with 5 to 8 items reflecting each one. We developed 16 of the 31 items based on our literature review ${ }^{1}$ and applied a 5-point scale with possible responses of 1 , not at all; 2, somewhat; 3, moderately; 4, mostly; and 5, fully. This scale was applied to help us understand and possibly study the development of and investment in academic coaching relationships and processes. We also incorporated 15 items from the mini-STERLinG, ${ }^{8}$ a tool developed by health professions educators in the Netherlands to evaluate teaching competencies that stimulate students' reflections in small groups. ${ }^{9}$ Initially, the STERLinG included 36 items with three subscales. ${ }^{9}$ Data reduction techniques resulted in the 15 -item scale we included in our survey. ${ }^{9}$ This scale used a 5-point Likert scale: 1, strongly disagree; 2 , disagree; 3 , neither agree nor disagree; 4, agree; 5, strongly agree. After initial development, we pilot tested the instrument using cognitive interviewing techniques. ${ }^{10}$

\section{Sample Size, Data Collection, and Data Analyses}

We used a conservative ratio of 15:1 for respondents per variable as the lowest cut point for our sample size target, ${ }^{11}$ which indicated at least 465 responses would be needed to conduct the factor analysis for each survey of our initially developed instruments for psychometric assessment. All research activities related to this study were reviewed and approved by OHSU's Institutional Review Board (IRB no. 10873). To collect medical student assessment of their coaches, we surveyed 144 medical students who entered the MD program in 2014 and 148 medical students who entered in 2015 . We received 327 responses from students in the 2014 cohort (75.7\% response rate) and 335 responses from students in the 2015 cohort (75.5\% response rate) for a total of 662 student responses included in analyses. To collect coaches' assessment of medical students, we surveyed 31 coaches and received responses from $22(71 \%)$ regarding the same 292 medical students from the 2014 and 2015 matriculated cohorts. These coaches provided 468 responses for 31 items on 15.1 medical students each (on average). The administration of the surveys for both the coaches and the medical students occurred between 7 and 8 months into their coaching relationship.

All surveys were web-hosted and data were de-identified for analyses after completion. All provided usable information for the factor analysis. Survey responses were analyzed at the item level and then were assessed for underlying patterns using exploratory factor analytic techniques. Exploratory versus confirmatory factor analysis was used because exploratory factor analysis aims to explore the relationships among the variables and does not have an a priori fixed number of factors. ${ }^{12}$ We were unsure how many constructs would be identified or how many variables would be needed to measure the emergent constructs accurately. Briefly, in multivariate statistics, exploratory factor analysis (EFA) is a statistical method used to uncover the underlying structure of a relatively large set of variables.

Using SPSS version 22, we conducted the factor analysis ${ }^{13-}$ ${ }^{15}$ using principal component analysis as the extraction method and Varimax (orthogonal) with Kaiser normalization as the rotation method for all items. Eigenvalues greater than 1.0 represented items that assimilated most of the variability reflected in participants' responses. Briefly, eigenvalues help to identify patterns within the data that contribute to measurement structures.

We calculated Cronbach's alpha coefficients (this is a measure of internal consistency or how closely related a set of items are as a domain, a measure of scale reliability) among items identified in the patterned constructs.

We created domain scores by summing component items responses and included descriptive statistics to characterize them. We also assessed the demographic characteristics of the medical students and coaches who contributed data to the surveys to describe the study sample that contributed to this psychometric assessment. Descriptive statistics were used to assess these characteristics to describe the pool of participants who contributed data to this psychometric study. 


\section{RESULTS}

Characteristics of medical students and faculty coaches who completed surveys used for this psychometric assessment are included in Table 1. The average age of medical students was 26.3, while for coaches, this was 44.1 (Table 1). The majority of both medical students and coaches was female and most were white and non-Hispanic. Most medical students were single without children, while most coaches were married and had children.

Table 2 illustrates the factor loadings (the part of the outcome from factor analysis that serves as a data reduction method designed to explain the correlations between observed variables using a smaller number of factors) for 18 of 31 survey items for students' assessment of coaches. The item analysis extraction loadings ranged from 0.61 to 0.85 for the retained items. Fourteen items with loadings lower than 0.60 were dropped, reducing the number of items on the assessments from 36 to 22. Online Appendix 1a (online) shows the items that were not retained on the student assessment of coaching survey. The pattern of variable groupings is also shown in Table 2 illustrating the four domains reflected in the data. Based on the groupings of questions within each cluster, we labeled the first domain promoting self-monitoring. We labeled the second domain relationship building, the third domain was labeled promoting reflective behavior, and the fourth domain was labeled establishing foundational ground rules.

The domain that most defined academic coaching for student respondents was domain 1: promoting self-monitoring, which had an eigenvalue of 18.5 for the five items, assimilated

Table 1 Characteristics of Medical Students and Coaches Who Completed Surveys

\begin{tabular}{|c|c|c|}
\hline $\begin{array}{l}\text { Demographics } \\
\text { characteristics }\end{array}$ & $\begin{array}{l}\text { Medical students } \\
(n=292)\end{array}$ & $\begin{array}{l}\text { Faculty coaches } \\
(n=22)\end{array}$ \\
\hline Mean age in years (SD) & $26.3(3.5)$ & $44.1(9.5)$ \\
\hline Range & $\begin{array}{l}22-42 \\
n(\%)\end{array}$ & $\begin{array}{l}31-64 \\
n(\%)\end{array}$ \\
\hline \multicolumn{3}{|l|}{ Gender } \\
\hline Male & $133(45.2)$ & $9(40.9)$ \\
\hline Female & $158(54.1)$ & $13(59.1)$ \\
\hline Fluid & $1(<1)$ & 0 \\
\hline \multicolumn{3}{|l|}{ Race } \\
\hline White & $221(75.6)$ & $16(72.7)$ \\
\hline $\begin{array}{l}\text { Asian or Pacific } \\
\text { islander }\end{array}$ & $50(17.1)$ & $2(9.1)$ \\
\hline $\begin{array}{l}\text { 1Slander } \\
\text { Black }\end{array}$ & $7(2.1)$ & 0 \\
\hline American Indian & $2(<1)$ & $4(18.2)$ \\
\hline Other & $12(4.1)$ & 0 \\
\hline \multicolumn{3}{|l|}{ Ethnicity } \\
\hline Hispanic & $12(4.1)$ & $0(0)$ \\
\hline Non-Hispanic & $280(95.9)$ & $22(100)$ \\
\hline \multicolumn{3}{|l|}{ Marital status } \\
\hline Single & $217(74.3)$ & $2(9.1)$ \\
\hline Married/partnered & $58(19.9)$ & $17(77.3)$ \\
\hline Separated & $2(<1)$ & $0(0)$ \\
\hline Divorced & $8(2.7)$ & $3(13.6)$ \\
\hline \multicolumn{3}{|l|}{ Have children } \\
\hline Yes & $10(3.4)$ & $18(81.8)$ \\
\hline No & $282(96.6)$ & $4(18.2)$ \\
\hline
\end{tabular}

$57.9 \%$ of the total variance, and had a Cronbach's alpha of 0.93 . The remaining items contributed to coaching to a lesser degree with eigenvalues ranging from 1.2 to 2.5 , variance assimilation between 3.7 and $7.7 \%$, with 4 or 5 items each, and with Cronbach's alphas at or above 0.90 .

Table 3 illustrates the obliquely rotated component loadings for 15 of 31 survey items for coaches' assessment of students. The item analysis extraction loadings ranged from 0.72 to 0.86 for retained items. Seventeen items with loadings lower than 0.70 were dropped. Online Appendix $1 \mathrm{~b}$ (online) shows the items that were not retained on the coaches' assessment of students' survey.

The pattern of variable groupings is also shown in Table 3, and two domains were reflected in the data. Based on the groupings of questions, we named the first domain the Practice of Coaching and the second domain Relationship Formation. The domain that most defined academic coaching for student respondents was domain 1 defined as the Practice of Coaching, which had an eigenvalue of 10.6 for 11 items, assimilated $58.7 \%$ of the total variance, and had a Cronbach's alpha of 0.96 . The second domain contributed to coaching to a lesser degree with an eigenvalue of 1.8 , variance assimilation of $10.1 \%$ for five items, and with a Cronbach's alpha of 0.88 . Versions of the survey can be found in Appendixes B and C (online).

\section{DISCUSSION}

This study conveys a psychometric analysis of internal structure validity and reliability for two instruments designed to measure the attributes of coaching from the perspectives of both the medical students and their faculty coaches, as part of undergraduate medical education. These instruments were initially developed based on our previously published definitions of coaching and proposed defining constructs. ${ }^{1}$ These analyses take this work a step further by grouping them into psychometrically viable domains and reducing the number of items needed to assess the relationship and the coaching process that occurs between medical students and their coach. Currently, we know of at least 25 other medical schools that use a coaching model to guide medical students toward becoming competent, master adaptive physician learners. We expect this number of schools to grow as competency-based, rather than time-based, education becomes the predominant model to prepare medical students to perform well in residency on their way toward independent clinical practice.

The instrument designed for medical students to complete revealed four relevant domains: promoting self-monitoring, relationship building, promoting reflective behavior, and establishing foundational ground rules. Two of these reflect the coaching relationship (relationship building and establishing foundational ground rules), while two reflect learning processes (promoting self-monitoring and promoting reflective behaviors). The four original constructs we developed (establishing relationship principles, conducting learner 
Table 2 Component Loadings for Retained Items on Medical Students Assessment of Coach

\begin{tabular}{|c|c|c|c|c|}
\hline \multirow[b]{2}{*}{ Survey items } & \multicolumn{4}{|c|}{ Component loadings } \\
\hline & $\begin{array}{l}\text { Promoting self- } \\
\text { monitoring }\end{array}$ & $\begin{array}{l}\text { Relationship } \\
\text { building }\end{array}$ & $\begin{array}{l}\text { Promoting } \\
\text { reflective } \\
\text { behavior }\end{array}$ & $\begin{array}{l}\text { Establishing } \\
\text { foundational ground } \\
\text { rules }\end{array}$ \\
\hline $\begin{array}{l}\text { How able or willing are you to learn about your own goals, } \\
\text { values and preferences when working with your coach?* }\end{array}$ & 0.71 & 0.30 & 0.23 & 0.28 \\
\hline $\begin{array}{l}\text { How able or willing are you to accept any weaknesses or } \\
\text { challenges your coach helps you understand?* }\end{array}$ & 0.74 & 0.26 & 0.18 & 0.17 \\
\hline $\begin{array}{l}\text { How able or willing are you to develop a shared agenda } \\
\text { with your coach, so that you make progress at your coaching } \\
\text { sessions?* }\end{array}$ & 0.75 & 0.29 & 0.20 & 0.27 \\
\hline $\begin{array}{l}\text { How able or willing are you to work with your coach to set } \\
\text { specific measurable, achievable goals?* }\end{array}$ & 0.79 & 0.25 & 0.16 & 0.23 \\
\hline $\begin{array}{l}\text { How able or willing are you to work with your coach to } \\
\text { select, organize and interpret information you need to } \\
\text { understand how to approach your goals toward achieving } \\
\text { success?* }\end{array}$ & 0.81 & 0.25 & 0.21 & 0.23 \\
\hline $\begin{array}{l}\text { My coach establishes a safe learning environment in the } \\
\text { group }^{\dagger}\end{array}$ & 0.25 & 0.75 & 0.20 & 0.26 \\
\hline $\begin{array}{l}\text { My coach shows commitment with the students of the } \\
\text { group }\end{array}$ & 0.20 & 0.79 & 0.14 & 0.26 \\
\hline My coach affirms my self-worth ${ }^{\dagger}$ & 0.27 & 0.79 & 0.16 & 0.26 \\
\hline $\begin{array}{l}\text { My coach stimulates me to take responsibility for my own } \\
\text { learning process }{ }^{\dagger}\end{array}$ & 0.24 & 0.78 & 0.23 & 0.18 \\
\hline $\begin{array}{l}\text { My coach encourages me to develop my own learning } \\
\text { objectives toward my professional development }\end{array}$ & 0.33 & 0.73 & 0.31 & 0.17 \\
\hline $\begin{array}{l}\text { My coach helps me become aware of emotions that } \\
\text { influence my behavior }\end{array}$ & 0.25 & 0.23 & 0.84 & 0.22 \\
\hline $\begin{array}{l}\text { My coach helps me investigate my behavior from a } \\
\text { distance }^{\dagger}\end{array}$ & 0.25 & 0.26 & 0.83 & 0.18 \\
\hline My coach helps me take a closer look at my thinking habits ${ }^{\dagger}$ & 0.26 & 0.24 & 0.85 & 0.19 \\
\hline My coach helps me recognize personal feelings ${ }^{\dagger}$ & 0.19 & 0.25 & 0.81 & 0.24 \\
\hline $\begin{array}{l}\text { To what extent do you feel the coaching relationship } \\
\text { represents a commitment from both you and your coach?* }\end{array}$ & 0.30 & 0.36 & 0.18 & 0.74 \\
\hline $\begin{array}{l}\text { To what extent do you feel like you and your coach are } \\
\text { responsible to each other?* }\end{array}$ & 0.31 & 0.35 & 0.27 & 0.68 \\
\hline $\begin{array}{l}\text { To what extent do you work with your coach to determine } \\
\text { what your success at OHSU will look like?* }\end{array}$ & 0.42 & 0.29 & 0.34 & 0.61 \\
\hline $\begin{array}{l}\text { To what extent do you trust your coach to be active in } \\
\text { helping you navigate your learning experiences?* }\end{array}$ & 0.38 & 0.41 & 0.21 & 0.64 \\
\hline Eigenvalues & 18.5 & 2.5 & 1.9 & 1.2 \\
\hline Percentage of total variance & 57.9 & 7.7 & 5.9 & 3.7 \\
\hline Number of items & 5 & 5 & 4 & 4 \\
\hline Scale mean (SD) & $22.1(3.8)$ & $23.1(3.1)$ & $15.5(3.7)$ & $17.5(3.4)$ \\
\hline Cronbach's alpha & 0.931 & 0.928 & 0.952 & 0.909 \\
\hline
\end{tabular}

*Scale responses: 1 , strongly disagree; 2, disagree; 3, neither agree nor disagree; 4, agree; 5, strongly agree

${ }^{+}$Scale responses: 1, not at all; 2 , somewhat; 3, moderately; 4, mostly; 5, fully

$S D$ standard deviation

assessments, developing and implementing an action plan, and assessing results and revising plans accordingly) map fairly closely to the domains that emerged from the factor analysis.

Establishing relationship principles links to relationship building and foundational ground rules, while conducting learner assessments and assessing results and revising plans accordingly link to promoting self-monitoring and promoting reflective behaviors. The construct on developing and implementing an action plan has some reflective features but does not fully map to the emergent domains. This may be because it is so action oriented. In any case, the emergent domains suggest that medical students appreciate the meaningfulness of the relationship they have with their coaches and that this is based on establishing "rules of engagement." Relationship development will become a critical skill for physicians practicing in any complex health care systems. The development of such relationships during undergraduate medical education will hopefully foster the development of similar relationships as medical students develop into competent physicians. We believe this will require growth in trustworthiness, emotional intelligence, and developing professional identity, concepts that reflected the variables that loaded onto the domains identified here.

The areas that reflect learning processes (promoting selfmonitoring and promoting reflective behaviors) are especially critical for developing physicians as these promote professional self-regulation, where students become adept at identifying the limits of their own skills and address these though continuing professional development. ${ }^{16}$ The variables we initially incorporated into the instrument and that loaded to reflect the promoting self-monitoring domain are reflective of the distinction between self-assessment (a more global judgment of one's ability in a particular domain) and self-monitoring (a moment-by-moment awareness of the likelihood that one 
Table 3 Component Loadings for Retained Items on Coaches Assessment of Medical Students

\begin{tabular}{|c|c|c|}
\hline \multirow[b]{2}{*}{ Survey items* } & \multicolumn{2}{|c|}{ Component loadings } \\
\hline & $\begin{array}{l}\text { The Practice of } \\
\text { Coaching }\end{array}$ & $\begin{array}{l}\text { Relationship } \\
\text { Formation }\end{array}$ \\
\hline $\begin{array}{l}\text { How able or willing are you to use reflective questioning techniques to help students gain insight into } \\
\text { their goals, values and preferences? }\end{array}$ & 0.79 & 0.32 \\
\hline $\begin{array}{l}\text { How able or willing are you to convey any weaknesses or challenges you think students are faced } \\
\text { with? }\end{array}$ & 0.78 & 0.32 \\
\hline $\begin{array}{l}\text { How able or willing are you to develop a shared agenda with your student, so that you make progress } \\
\text { at your coaching sessions? }\end{array}$ & 0.81 & 0.28 \\
\hline $\begin{array}{l}\text { How able or willing are you to work with your student in setting specific measurable, achievable } \\
\text { goals? }\end{array}$ & 0.86 & 0.20 \\
\hline $\begin{array}{l}\text { How able or willing are you to work with your student to select, organize and interpret information } \\
\text { they need to understand how to approach their goals to achieve success? }\end{array}$ & 0.84 & 0.25 \\
\hline $\begin{array}{l}\text { How able or willing are you to work with your student to determine timelines within which they can } \\
\text { meet their goals? }\end{array}$ & 0.82 & 0.29 \\
\hline $\begin{array}{l}\text { How able or willing are you to monitor your student's progress in the program and provide guidance } \\
\text { to help them develop toward meeting their goals? }\end{array}$ & 0.85 & 0.23 \\
\hline How able or willing are you to help your student identify problems they are having? & 0.79 & 0.20 \\
\hline $\begin{array}{l}\text { How able or willing are you to provide guidance that helps your student solve the problems } \mathrm{s} / \text { he is } \\
\text { having, such as finding needed resources? }\end{array}$ & 0.81 & 0.33 \\
\hline $\begin{array}{l}\text { How able are willing are you to help your student characterize the values and preferences they have } \\
\text { about the type of medicine they would like to practice? }\end{array}$ & 0.79 & 0.27 \\
\hline $\begin{array}{l}\text { To what extent do you feel the coaching relationship represents a commitment from both you and your } \\
\text { student? }\end{array}$ & 0.17 & 0.84 \\
\hline $\begin{array}{l}\text { To what extent do you feel like you and your student are responsible to each other in the work you do } \\
\text { together? }\end{array}$ & 0.24 & 0.82 \\
\hline $\begin{array}{l}\text { To what extent do you and your student inspire each other to learn to make the coaching process as } \\
\text { good as it can be? }\end{array}$ & 0.37 & 0.72 \\
\hline To what extent do you trust your student to be active in helping to navigate their learning experiences? & 0.29 & 0.75 \\
\hline $\begin{array}{l}\text { To what extent do you trust your student to be honest in helping to navigate their learning } \\
\text { experiences? }\end{array}$ & 0.26 & 0.75 \\
\hline Eigenvalues & 10.6 & 1.8 \\
\hline Percentage of total variance & 58.7 & 10.1 \\
\hline Number of items & 11 & 5 \\
\hline Scale mean (SD) & $42.0(6.5)$ & $22.4(2.7)$ \\
\hline Cronbach's alpha & 0.960 & 0.878 \\
\hline
\end{tabular}

*Scale responses: 1 , not at all; 2, somewhat; 3, moderately; 4, mostly; 5, fully

SD standard deviation

maintains the skills/knowledge needed to act in a particular situation). ${ }^{16}$ Research has shown that physician selfassessment slows over a career. ${ }^{17}$ What is needed, though, is lifelong development of skills and knowledge over time throughout a physicians' career.

The idea of physicians becoming lifelong learners has greatly advanced, given the amount of rapid expansion of medical knowledge, procedural technologies, and studies on patient preferences. Master adaptive learning now applies learning theory to the learner, the teacher, and the learning environment, illustrating the complexity of skill development now expected of practicing physicians. ${ }^{18}$ In addition, learner-centeredness has become essential, as learners drive their educational processes and coaches and students share the responsibility for the pathways and content of learning, where getting and processing feedback is crucial. ${ }^{3,}{ }^{19}$ Coaching has the potential to help medical students develop into master adaptive learners, and the idea that the instruments we have developed and validated will foster an understanding how these complex relationships and reflective/selfmonitoring skills develop over time and lead to success in UME, GME, and beyond is exciting. We plan to pursue these areas as our program matures.
The instrument validated for coaches' assessment of students revealed two domains, the Practice of Coaching and Relationship Formation, indicating that they perceive similar importance to both the coaching relationship and the coaching process as medical students did. There is much to be learned about how being a coach influences these faculty members' approaches as teachers, clinical preceptors, advisors, and mentors, and vice-versa. It is likely that teasing out these concepts into measurable constructs would reveal some overlap. Nevertheless, the novel role of coaching designed to enhance the development of medical students into physicians who are ready to undertake residency training using comprehensive approaches to learner assessments and reflections on the learning process is very compelling. There is much to be learned in this area; this is an initial step toward validated measurement.

In our own program, we use the two evaluation forms in tandem yearly to perform program evaluation and give formative feedback to both the coach and the learner. For institutions using a different coaching model or that include coaching within an advising or mentoring relationship, we believe the instruments could still offer value. These instruments also have the potential to measure coaching and create programmatic outcomes goals. Coaching programs, like the one at 
OHSU, can be costly in terms of money and time. This investment needs objective justification, such as those that these measurement instruments can provide. For example, these instruments could be used for future study on the impact coaching has on student performance, resilience, career satisfaction, and patient outcomes. They also have potential to help programs develop objectives for orienting faculty and students to the coaching process and may help illuminate individual or across-program faculty and student development needs.

As with any factor analysis, we developed these tools and validated them in our own coaching program, with a unique set of learners, coaches, and program definitions to other schools. Other medical schools who are using coaching programs to guide competency development and use these tools would conduct a confirmatory factor analysis, which we are also planning to conduct, or at least reassess the alpha coefficients to be sure they are performing similarly in their programs. In addition, with the validity evidence we now have for these tools, we can pursue additional longitudinal studies that inform how the coaching relationship develops over time, how it operates to enhance learner performance, and how it assists medical students prepare for a selected discipline in medicine and for residency training. In addition, more research will be needed on the nesting effects of multiple respondents to one coach and one coaches assessments of multiple learners and how these affect coaching constructs. Though we evaluated this instrument with medical students early in their programs, conducting a reassessment of students in the clinical curriculum (third or fourth years), or even more advanced learners such as residents or fellows, and assessing coaching relationships may shed additional light on students coaching needs and may even be useful even for practicing attendings. We do know that scheduling coaching sessions during the clinical curriculum is very challenging. These are areas we plan to pursue but that are beyond the scope of the current paper.

A strength of this work is the in-depth analysis of the coaching literature published in prior work ${ }^{1}$ that provided the foundation for the development of our instruments. All the alpha coefficients measured in the domains we identified in our analyses ranged between 0.88 and 0.96 , which are very robust values. We look forward to learning what is needed to support competency-based medical education.

In conclusion, we have developed and validated robust tools designed to assess coaching relationships and processes that are key to competency-based education. This work advances our knowledge of assessment of academic coaching in undergraduate medical education.

Acknowledgments: The authors gratefully acknowledge Patrick Chung, BS, and Elaine Waller, BS, for their assistance with data capture and management.

Corresponding Author: Patricia A. Carney, PhD; Oregon Health \& Science University, 3181 SW Sam Jackson Park Rd., Mail Code: FM, Portland, OR 97239, USA (e-mail: carneyp@ohsu.edu).
Funding Information This work was supported by Dean's Office at Oregon Health \& Science University, an Accelerating Change in Medical Education Grant from the American Medical Association, and the Research Program in Family Medicine at Oregon Health \& Science University.

\section{Compliance with Ethical Standards:}

All research activities related to this study were reviewed and approved by OHSU's Institutional Review Board (IRB no. 10873).

Conflict of Interest: The authors declare that they do not have a conflict of interest.

Publisher's Note: Springer Nature remains neutral with regard to jurisdictional claims in published maps and institutional affiliations.

\section{REFERENCES}

1. Deiorio MN, Carney PA, Kahl LE, Bonura EM, Miller-Juve A. Coaching: A New Model for Academic Achievement. Med Educ Online 2016, 21(1): doi:https://doi.org/10.3402/meo.v21.33480 (Accessed 12/19/17_.

2. Sargeant $\mathbf{J}$, Lockyer $\mathbf{J}$, Mann $\mathbf{K}$, et al. Facilitated reflective performance feedback: developing an evidence- and theory-based model that builds relationship, explores reactions and content, and coaches for performance change (R2C2). Acad Med 2015; 90: 1698-706.

3. Schumacher DJ, Englander R, Carraccio C. Developing the master learner: applying learning theory to the learner, the teacher, and the learning environment. Acad Med 2013; 88: 1635-45.

4. Skochelak SE, Stack SJ. Creating the medical schools of the future. Acad Med, 2017; 92(1): 16-19.

5. Kuhn TL. Historical foundations of academic advising. In: Gordon VN, Habley WR, Grites TJ, eds. Academic advising: a comprehensive handbook. 5th ed San Francisco, CA: Jossey-Bass; 2008, pp. 3-16.

6. D'Abate CP, Eddy ER, Tannenbaum SI. What's in a Name? A LiteratureBased Approach to Understanding Mentoring, Coaching, and Other Constructs That Describe Developmental Interactions. Human Resource Development Review 2003 2: 360.

7. Cummings TG, Worley CG. Coaching and mentoring (in) Organizational development and change. Mason, $\mathrm{OH}$ : South-Western Cengage Learning; 2009.

8. Schonrock-Adema J, Schaub-De Jong MA, Cohen-Schotanus J. The development and validation of the SEERLinG: A practical, valid and reliable tool to evaluate teacher competencies to encourage reflective learning.

9. Schaub-De Jong MA, Schonrock-Adema J, Cohen-Schotanus J, Dekker H, Verkerk MA. Development of a student rating scale to evaluate teachers' competencies for facilitating reflective learning. Med Educ, 2011; 45:155-165.

10. Drennan J. Cognitive interviewing: verbal data in the design and pretesting of questionnaires. Journal of Advanced Nursing 2003;41(1):57-63.

11. Mundfrom DJ, Shaw DG, Tian LK, Minimum Sample size recommendations for conducting factor analyses. Int $\mathrm{J}$ of Testing, 2005; 5(2): 159-168.

12. Rahn M. Factor Analysis: A short Introduction, Part 3 - The difference between confirmatory and exploratory factor analysis. Making Statistics Make Sense: https://www.theanalysisfactor.com/confirmatory-and-exploratory-factor-analysis/ (Accessed 11/19/18).

13. Thompson B. Exploratory and confirmatory factor analysis: Understanding concepts and applications. Washington, DC, US: American Psychological Association, 2004.

14. Schmitt N. Uses and abuses of Coefficient Alpha. Psych Assessment 1996;8(4):350-353.

15. Ponterotto JG, Ruckdeschel DE. An overview of coefficient alpha and a reliability matrix for estimating adequacy of internal consistency coefficients with psychological research measures. Perceptual and Motor Skills 2007; 105:997-1014

16. Nothnagle M, Goldman R, Quirk M, Reis S. Promoting self-directed learning skills in residency: A case study in program development. Academic Medicine, 2010;85(12):1874-1879. 
17. Eva KW, Regehr G. Exploring the divergence between self-assessment and self-monitoring. Advances in Health Science Education, 2011;16(3):311-329.

18. Davis DA, Mazmanian PE, Fordis M, Van Harrison $\mathbf{R}$, Thorpe KE, Perrier L. Accuracy of physician self-assessment compared with observed measures of competence: A systematic review. JAMA. 2006;296: 1094-1102

19. Telio RG, Ajjawi R. Feedback and the educational alliance: examining credibility judgments and their consequences. Medical Education, 2016; 50(9):933-942. 